\title{
A prática docente num contexto heterogêneo de aprendizagem: 0 olhar sobre $o$ aluno ideal e real
}

\author{
Nogueira, Lourrane Almeida ${ }^{1}$ \\ Oliveira-Mendes, Solange Alves de ${ }^{2}$
}

\section{Resumo}

Neste estudo, analisamos a concepção de uma professora acerca do conceito de "aluno ideal". $\mathrm{Na}$ ocasião da pesquisa, a mestra atuava na educação infantil com crianças de cinco anos de idade numa escola da rede particular do Distrito Federal. Investigamos como a concepção de criança e infância influenciava na maneira de ensinar e tratar os alunos reais que, de fato, estavam na sua sala de aula. Procuramos entender, de modo específico, se a infância era valorizada pela professora dentro do seu próprio conceito de aluno ideal e quais as implicações de suas expectativas na relação professor-aluno e aluno-aluno. Recorremos a autores, tais como: Ariès (1981); Del Priore (1991); Faria (2005), entre outros, cujo enfoque recai na análise da infância ao longo dos séculos no Brasil, bem como numa esfera mais ampla. Analisamos, ainda, como a infância está inserida, na contemporaneidade, no contexto escolar. Optamos pela pesquisa qualitativa e, como instrumentos metodológicos, recorremos à observação participante e à entrevista semiestruturada com a professora regente. Como resultado, ressaltamos que havia expectativas, por parte da docente, acerca dos alunos, no concernente ao seu conceito de aluno ideal. Esse pressuposto refletia diretamente em suas ações didáticas, visto que, aqueles aprendizes que demonstravam bom comportamento, rendimento cognitivo satisfatório, eram tratados de forma diferente dos demais. Em contrapartida, não escondia sua frustração diante daqueles que não se inseriam nesse contexto por ela idealizado.

\section{Educação Infantil. Ensino. "Aluno Ideal".}

\section{Abstracto}

En este estudio, se analizó la concepción de una profesora sobre el concepto de "alumno ideal". En el momento de la investigación, la maestra trabajaba en la educación infantil con niños de cinco años en una escuela privada en el Distrito Federal. Investigamos cómo la concepción de la infancia y la niñez influyeron en la manera de enseñar y tratar a los estudiantes reales, que de hecho, estaban en su salón de clases. Buscamos entender, específicamente, si la niñez, fue valorada por la profesora dentro de su propio concepto de alumno ideal y cual las implicaciones de sus expectativas en la relación profesor-alumno y alumno-alumno. Utilizamos autores, como Aries (1981); Del Priore (1991); Faria (2005), entre otros, cuya atención se centra en el análisis de la infancia a lo largo de los siglos en Brasil, así como en una esfera más amplia. Hemos analizado también como se inserta la infancia, en la época contemporánea, en el contexto escolar. Elegimos la investigación cualitativa y, como

\footnotetext{
1 Graduanda do curso de Pedagogia - Faculdade de Educação - Universidade de Brasília.
}

2 Professora da Faculdade de Educação da Universidade de Brasília. 
herramientas metodológicas, se utilizó la observación participante y la entrevista semiestructurada con la maestra regente. Como resultado, resaltamos que había expectativas por parte de la profesora, con respecto a su concepto de alumno ideal. Este presupuesto se refleja directamente en sus acciones didácticas, una vez que, aquellos aprendices que han demostrado buena conducta, rendimiento cognitivo exitoso, fueron tratados de manera distinta de los demás. Por otro lado, no ocultó su frustración con los alumnos que no se han insertado en ese contexto por ella idealizado.

\section{Educación Infantil. Enseñanza. "Alumno Ideal".}

\section{Introdução}

Ao longo dos séculos, a criança tem sido vista de diferentes maneiras. $\mathrm{Na}$ idade média, em um contexto mundial, era tratada e vestida como um adulto em miniatura, representações que podemos ver, até mesmo, nas produções artísticas da época. Crianças, desde bem pequenas, já eram inseridas no ambiente de trabalho como aprendizes, onde Ihes eram ensinados diversos ofícios.

De acordo com Del Priore (1991), aqui no Brasil, no século XIX, o mesmo se deu, quando até mesmo filhos de escravas, que foram libertos pela lei do Ventre Livre, tinham que trabalhar para os seus senhores, que os viam de uma forma não tão diferente de suas mães. Pequeninos, em São Paulo, eram levados para trabalhar nas fábricas, que, visando apenas o maior lucro, explorava seus serviços, sem sequer dar algum tipo de remuneração.

E o que dizer da infância dessas crianças? Não podemos afirmar que essa não existia, mas certamente era prejudicada e diminuída pelo seu modo de vida. Como realçou Ariès (1981), em algum tempo da história, "a infância era apenas uma fase sem importância, que não fazia sentido fixar na lembrança" (p.47).

Considerando esse contexto social mais amplo, interessamo-nos por analisar como a criança tem sido vista e tratada dentro da escola e da sala de aula, e como a infância é percebida pelo olhar do professor. 


\section{A criança nos contextos mundial e brasileiro}

Atualmente, a criança tem um grande papel na sociedade, sendo vista como um sujeito exigente, questionador, com suas singularidades. Realçamos, ainda, que é, de forma crescente, "objeto de um grande mercado consumidor, incluindo as vastas formas de entretenimento", conforme enfatizam Nascimento, Brancher e Oliveira (2008, p.05). Acrescentamos, ainda, documentos oficiais, no caso brasileiro, que vêm sendo elaborados a seu favor, a exemplo do Estatuto da Criança e do Adolescente (1990), além de pesquisas dedicadas à infância. Mas, conforme analisaremos, isso nem sempre foi assim. O valor dado às crianças e ao sentimento de infância é bem atual, deixando de serem percebidos, ou pelo menos não assumiam grande importância, entre os séculos $X I$ e $X X$.

Autores como Ariès (1981) e Del Priore (1991) trazem, em seus escritos, a história da criança e da infância entre os séculos XI ao XX. Queremos enfatizar, também, que, apesar de alguns autores utilizarem essas expressões como sinônimos, estamos cientes da diferença dessas concepções, sendo a criança compreendida como ser histórico, cultural e social, e a infância "se refere a uma determinada etapa da vida da pessoa", de acordo com Heywood (2001, p.22).

Conforme Ariès (1981), na idade média a infância era reduzida apenas ao momento em que a criança não conseguia viver sozinha, sendo vista como um ser frágil que, consequentemente, necessitava do outro. Logo que ela começava a se desenvolver fisicamente, já era inserida no mundo dos adultos, mostrando que, de forma geral, não se existia a consciência da particularidade infantil.

A indiferença pela infância era evidente nos trajes usados por elas, que se assemelhavam a de adultos. Diferente de hoje, a vestimenta era incômoda, pouco confortável, impedia que ficassem a vontade para brincar e se divertir, tirando essa característica básica do mundo infantil. "Assim que a criança deixava os cueiros, ou seja, a faixa de tecido que era enrolada em torno do seu 
corpo, era vestida como homens e mulheres da sua condição", de acordo com Ariès (1981, p.59).

O autor traz outro aspecto que expressava o descaso com o sentimento de infância que era a igualdade existente nos jogos e brincadeiras entre adultos e crianças. Não existia uma separação como hoje, de modo que os mesmos jogos eram comuns a ambos. Ao término da primeira infância, considerada até os seis anos, os pequeninos já eram introduzidos aos jogos de azar, cartas, aprendendo, inclusive, a caçar, usar armas. Não existiam representações coletivas que as crianças não tivessem seu lugar, se pequenas demais, estariam com mulheres que cuidavam delas, se não, estariam "trabalhando como aprendizes, servindo como pajens de um cavaleiro ou estando em um ateliê". (ARIÈS, 1981, p. 145).

No âmbito mundial, Ariès (1981) enfatiza que o sentimento de infância começa a ser percebido a partir do século XVII. Nesse momento, no seio familiar, a criança começa a ser paparicada, sendo vista como objeto de diversão e distração aos olhos dos adultos. No contexto artístico, a personalidade que se admitia existir nas crianças, o sentido poético e familiar que se atribuía a sua particularidade, começava a ser expresso nas obras. Até mesmo na vestimenta dos pequenos, notamos a grande mudança, visto que, nesse contexto, eles tinham um traje especial que se distinguia dos adultos.

No Brasil, o descaso com essa etapa também se evidenciou. De acordo com Del Priore (1991), em 1871, no Rio de Janeiro, num contexto de escravidão, o mesmo acontecia com os filhos das escravas que haviam sido declarados livres pela Lei do Ventre Livre. Até os três anos de idade, deveriam permanecer com suas mães, mas, ultrapassada essa primeira fase da idade infantil, a criança já ia adquirir certa autonomia que marcaria uma virada na sua vida. O curto período dos três aos sete anos na vida da criança é de iniciação aos comportamentos sociais tanto com a sociedade dos seus senhores como com a comunidade escrava. Nessa idade, ela começará a prestar serviços regulares como mensageiro, carregador de encomendas ou pajem, e, também, perceberá o que são os castigos corporais. (DEL PRIORE, 1991) 
Em outro contexto, agora nas fábricas em São Paulo, num período capitalista, em meados de 1870, crianças eram levadas precocemente para trabalhar nas indústrias. Para a vantagem dos empresários, elas recebiam salários irrisórios ou, se estivessem na condição de aprendiz, nem sequer recebiam remuneração, ampliando o lucro do empresariado. (DEL PRIORE, 1991). Até em 1912, era bastante expressivo o uso da mão de obra menor na indústria, principalmente têxtil. Pesquisas dizem que "os menores representam pouco mais de $30 \%$ do total de operários nas fábricas na capital de São Paulo. Em 1919, o mesmo departamento constata que os menores correspondem a cerca de $40 \%$ do total de mão de obra empregada", de acordo com Del Priore (1996, p. 114).

A situação da criança e a preocupação com a mesma começará a mudar com a Constituição de 1934, que "proibirá o trabalho para crianças menores de 14 anos, o trabalho noturno para menores de 16 e, nas indústrias insalubres, aos menores de 18 anos" (DEL PRIORE, 1991, p.148). Nos anos seguintes, continuamos a notar o interesse pelo menor, quando em 1969 a "Emenda Constitucional traz a obrigatoriedade do ensino primário público àqueles entre 7 e 14 anos". E, por fim, na Constituição de 1988, a idade mínima para trabalhar era 14 anos, mas agora essas crianças "teriam garantias trabalhistas e previdenciárias, igualdade na relação processual", tudo isso garantido pela lei, segundo Del Priore (1991, p. 148)

Dentro desse contexto de trabalho das fábricas, aonde as famílias necessitavam trabalhar para sobreviver e não tinham com quem deixar seus filhos pequenos, como afirma Paschoal e Machado (2009, p. 80), "utilizavam os serviços das mães mercenárias, que não trabalhavam nas fábricas, mas vendiam seus serviços para abrigarem e cuidarem dos filhos de outras mulheres". Foi por causa dessa necessidade, que começou a se pensar em instituições infantis, tanto no Brasil quanto em outros países, assim, as primeiras instituições criadas tinham por objetivo assistir os filhos das mães trabalhadoras. Porém, algumas dessas também se preocupavam com a 
educação, fornecendo o ensino de trabalhos manuais, boas maneiras, e, também, ajudando a criança a desenvolver a leitura e a escrita.

Com a preocupação de atendimento para todas as crianças, não importando a sua classe social, começa o processo de regulamentar, por meio de leis, o trabalho nessas instituições. Assim, foi produzida a Constituição Federal de 1988, que, em seu artigo 208, o inciso IV enfatiza: "[...] O dever do Estado para com a educação será efetivado mediante a garantia de oferta de creches e pré-escolas às crianças de zero a seis anos de idade" (BRASIL, 1988). Além disso, dois anos depois, foi aprovado o Estatuto da Criança e do Adolescente, e, em 1996, a Lei de Diretrizes e Bases da Educação Nacional (LDBEN, 9.394) que define e regulariza a organização da educação brasileira com base nos princípios presentes na Constituição, conforme realçam Paschoal e Machado (2009).

Como vimos, nem sempre a infância foi valorizada, tanto no mundo como em cidades brasileiras, mas é pensando nesse contexto que buscamos compreender como as crianças são vistas hoje no meio escolar e quais as expectativas dos educadores sobre elas.

\section{Concepções de criança ideal e real no contexto escolar}

Conforme pontuamos em seção anterior, a infância é um direito inerente a toda criança. A partir de seis anos, estão constituídas no âmbito escolar, conforme explicita a Lei de Diretrizes e Bases da Educação Nacional (LDBEN 9.394/1996) em seu artigo 32 o qual enfatiza que o ensino fundamental é obrigatório, iniciando-se aos seis anos de idade e tem por objetivo a formação básica do cidadão.

Pesquisas vem apontando que, na prática de sala de aula, podem ser abertos espaços para que as crianças conversem, dialoguem, expressem suas opiniões, principalmente umas com as outras. Sobre esse assunto, Faria (2005) pontua que,

os espaços, para isso, devem permitir, também, a realização de atividades individuais, em pequenos e grandes grupos, com e sem a intervenção do adulto (s); atividades de concentração, 
de folia, de fantasia; atividades para o movimento de todo o tipo, propiciando a imersão de todas as dimensões humanas. (p. 79).

Mas isso tem acontecido nas escolas? Vemos que, na maior parte do tempo, em algumas instituições, as crianças passam sentadas, ouvindo seu professor. O único momento para lazer ou um aprendizado mais espontâneo, realmente são os poucos minutos de recreio. E o que dizer daqueles que não obedecem ao professor em algum momento da aula? Logo perdem a oportunidade de brincar e, como consequência, ficam sentados na sala, pensando no que fizeram, de acordo com Neves (2005).

Conforme Strazzacappa (2001), a representação do bom aluno que a escola tem como ideal é a criança comportada, ou seja, crianças que permanecem quietas, sentadas em suas carteiras enfileiradas e que são produtivas. Por isso, hoje notamos a constante frustração dos professores que reclamam da indisciplina dos alunos e a sua dificuldade em lidar com esses alunos reais que estão nas escolas.

Não queremos enfatizar que a criança deve fazer tudo o que quer, na hora que quer, mas reconhecemos a importância de se ajustar o ensino às singularidades infantis, inclusive, priorizando atividades que articulem o ensino dos diferentes objetos de conhecimento às dimensões do brincar, da ludicidade.

Outro aspecto que não podemos deixar de mencionar tem a ver com as expectativas dos professores com relação aos seus alunos. Essa expectativa pode afetar o desempenho dos aprendizes? O estudo realizado por Bzuneck (2001) sobre as crenças de auto eficácia dos professores, aponta que

(...) os alunos que reagem positivamente levam seus professores a acreditarem mais em suas capacidades, motivando-os a continuar planejando e propondo novos e excelentes desafios à classe. Já uma turma não responsiva, faz 0 professor se questionar se realmente possui competências necessárias para o ensino, o que representa dúvidas sobre a sua auto eficácia (p.125). 
Isso nos permite dizer que os professores podem construir melhores expectativas sobre os seus alunos quando estes reagem da maneira esperada por ele. "De certa forma, o educador prevê um determinado comportamento como sendo o ideal e espera que os alunos se aproximem ao máximo do que foi pré-determinado", é o que apontam Univali e Donaduzzi (2004, p. 8).

A seguir, nossos instrumentos e procedimentos metodológicos.

\section{Metodologia}

Esse estudo buscou analisar as concepções de aluno ideal por parte de uma docente que atuava, em 2016, na educação infantil numa escola particular situada no Distrito Federal, com crianças de cinco anos.

Para isso, priorizamos algumas questões: na ótica do professor, o que é o aluno ideal? Que características possui? Essa expectativa de ter alunos ideais influencia na maneira de ensinar e tratar os alunos reais que, de fato, estão nas salas de aula? O aluno considerado ideal, na concepção do professor, é realmente o melhor dentro da classe?

Optamos por uma pesquisa de cunho qualitativo, pois, de acordo com Gerhardt e Silveira (2009, p. 32), “a pesquisa qualitativa se preocupa com aspectos da realidade que não podem ser quantificados, centrando-se na compreensão e explicação da dinâmica das relações sociais". Assim, foi realizada uma entrevista semiestruturada com a professora regente, objetivando entender suas concepções acerca dos alunos que tinha em sala. Acompanhamos a prática dessa docente e, para esse estudo, recorremos a 10 relatos de observações realizadas no primeiro semestre de 2016 . O objetivo foi apreender, na prática, o tratamento didático dado aos aprendizes em sala de aula, considerando suas singularidades.

\section{Análise e discussão dos resultados}

Nosso intuito é articular os dados obtidos na entrevista com os aspectos observados na prática docente acompanhada.

Ao apreendermos a concepção de criança ideal, as expectativas que a mestra tinha no início do ano letivo e as implicações no ensino. Ela revelou que 
o tema infância remete à criança e destacou algumas características importantes dessa fase: a "alegria, a brincadeira, a descontração, o desejo de brincar o tempo inteiro". Também enfatizou sentimentos, tais como: amor, sinceridade, companheirismo, carinho; conceito que se aproxima do defendido por Carvalho (2011, p.2) ao realçar que "a infância passa a ser vista como um tempo em si, tempo de brincar, jogar, sorrir, chorar, sonhar, desenhar, colorir". A mestra seguiu destacando:

Pelas crianças, elas brincariam o tempo inteiro, querem gastar as energias, elas querem o tempo todo estar livres para fazer 0 que querem. Mas com jeitinho, a gente consegue fazer com que elas entendam, que, além das brincadeiras, além desse momento que elas querem passar o tempo todo brincando, elas precisam, também, se dedicar para aprender.

Interessante enfatizar que a brincadeira não era vista pela professora como um momento rico de aprendizado, o que parece indicar uma dissociação na tríade: educar, brincar e cuidar.

Por outro lado, a mestra admitiu que a brincadeira desperta a curiosidade, o desejo de aprender coisas novas, logo, em sua compreensão, esse era um contexto propício para trabalhar, por exemplo, com os eixos de leitura e escrita nessa etapa da escolarização, acentuando a relação do aprender com a ludicidade.

Vemos o quanto o conceito de infância mudou ao longo do tempo, de modo que essa particularidade da infância: a brincadeira acoplada à construção do saber não era valorizada, nem tampouco os comportamentos infantis tidos como importantes. A infância era reduzida apenas ao momento em que a criança não conseguia viver sozinha, de acordo com Ariès (1981).

No que se refere ao tratamento das especificidades da infância no contexto da sala de aula, ressaltamos que é muito importante que a escola permita que as crianças demonstrem comportamentos naturais a sua idade, visto que elas estão, desde bem cedo, inseridas neste contexto.

A brincadeira, por exemplo, é crucial para apreendermos a inserção da criança na sociedade, já que, nesse momento, ela assimila crenças, costumes, 
regras. Além disso, passa a ser vista como uma estratégia poderosa para 0 aprendizado do aluno, tanto que, cada vez mais, ouvimos falar dos recursos lúdicos que são utilizados em sala, objetivando contribuir no processo educacional e, em particular, no desenvolvimento da criança.

A professora afirmou ser normal da faixa etária o aluno demonstrar esses aspectos da infância, apontando que "é impossível uma criança ficar na sala de aula sem querer brincar. É impossível ela não perder a concentração". Porém, logo que realçou isso, já ressaltou que o professor, nesse momento, deve ensinar os limites para que a criança saiba o que fazer e o que não fazer em cada momento da jornada na escola. Mais uma vez, a concepção da mestra parece ir na direção de uma desarticulação entre os momentos de brincadeira e de uma aprendizagem legitimada na instituição educativa.

Ainda sobre esse assunto, segundo a professora, é possível pensar em várias estratégias didáticas para controlar os alunos na hora que for necessário. Destacou que todos precisam pensar:

\footnotetext{
O que eu faço para melhorar a desconcentração desse aluno? Para puxar a atenção dele para mim? Para que ele fique com a atenção voltada para mim? O que eu faço para atrair esse aluno? O que eu faço para que o aluno não fique conversando o tempo todo, para que ele não se prejudique nem prejudique os colegas? Tudo isso aí é uma adaptação no dia a dia, quando a gente vai conhecendo o aluno, a gente vai traçando metas e traçando meios para trabalhar com ele.
}

Para obter um bom comportamento dos alunos, ao iniciar a aula, a professora costumava designar o lugar que cada um iria sentar e sempre colocava esses alunos perto de sua mesa, pois, assim, conseguia ter um controle maior da turma. Outra estratégia adotada por ela era mostrar que cada ação que eles tinham gerava uma consequência. Nesse caso, quando conversavam muito, corriam dentro da sala ou batiam uns nos outros, ela fazia um rostinho triste no quadro e escrevia o nome desses alunos. Isso significava que, aquele que tinha seu nome escrito no quadro, não iria para o parque brincar. la ficar na sala com a professora na hora do intervalo. 
Essa alternativa ocorreu já na primeira observação de aula. Nesse dia, a professora chegou a sala e, como de costume, pediu as agendas e a atividade de casa de todos os alunos. Uma das crianças estava fora de sala e não queria entrar. Ela se ausentou para buscá-lo e ficou conversando com ele por cerca de três minutos. Nesse período, dois alunos começaram a correr dentro da sala, brincando de luta. Logo que a mestra entrou e viu o que estavam fazendo, gritou:

Felipe! Eu deixei você ficar correndo na sala? Você tem que ficar sentado como os outros. Vou colocar uma carinha triste aqui no quadro agora e vou colocar seu nome embaixo. Agora pra você ir pra o parque vai ter que merecer (1ำ relato de observação)

No que se refere à concepção da professora acerca do aluno ideal, partindo da entrevista realizada, mencionou as dificuldades que existiam na contemporaneidade em sala de aula, já que a maior parte dos alunos parecia não apresentar limites ou, mesmo, o respeito pelos colegas e professores. Por isso, afirmou ser esses dois aspectos imprescindíveis no aluno ideal. Segundo a docente, a criança tem que "entender o que ela pode e o que não pode fazer, que na escola existem regras que ela precisa entender, regras que são trabalhadas no dia a dia das crianças".

Para ela, a criança ideal entende que existe um tempo para tudo: brincar, conversar, fazer silêncio, ouvir, momento para realizar as atividades. Afirmou, ainda, que a compreensão do funcionamento da escola, das regras, irá refletir no aprendizado dela, pois, como está sempre atenta aos comandos da professora e realiza as atividades na hora correta, com certeza vai ter um melhor desenvolvimento com relação ao conteúdo que está sendo trabalhado.

Esse conceito é realçado por Strazzacappa (2001), visto que a representação do bom aluno que a escola tem como ideal é a "criança comportada", ou seja, crianças que permanecem quietas, sentadas em suas carteiras enfileiradas e que são produtivas do ponto de vista do conteúdo ministrado. 
O relato da docente se aproximou com a prática observada, inclusive um dos alunos que, para ela, poderia ser um modelo de aluno ideal, apenas não era por conta do seu comportamento em sala de aula. Na descrição que fez desse aprendiz, pontuou:

nota 10 em relação ao desenvolvimento cognitivo. A letra linda, a coordenação motora excelente, muito inteligente, pega as coisas no ar, observa tudo, presta atenção em tudo, porém, no comportamento, de vez em quando, ultrapassa os limites, de vez em quando, fica bem agitado.

Esse relato é claro quanto às expectativas que a professora tinha acerca do aluno ideal. Acreditamos que esse processo não ocorre de forma isolada, de modo que há interferência direta da família, da gestão da escola. Tais aspectos não são objeto desse estudo, mas as concepções docentes acerca do aluno ideal. No caso anteriormente descrito, a criança, na ótica da professora, tinha características de um excelente aluno, mas, ainda assim, não era visto como um educando ideal. A seguir, destacamos um trecho do $8^{0}$ relato de observação, em que a professora reagiu por conta da conversa excessiva no horário da aula, referente ao mesmo aluno por ela mencionado anteriormente:

Por que você faz isso João? ${ }^{3}$ Você é tão inteligente, é caprichoso, sua letrinha é linda, mas por que você é tão desobediente? Por que você não faz o que eu peço pra você?

A professora se alegrava com o bom desempenho do aluno, mas ficava frustrada por ele não ter o comportamento que ela esperava. "De certa forma, o educador prevê um determinado comportamento como sendo o ideal e espera que os alunos se aproximem ao máximo do que foi pré-determinado", é o que afirmam Univali e Donaduzzi (2004, p. 8).

Outro aluno mencionado durante a entrevista como um aluno ideal foi o Mateus. Ela se referiu ao aluno da seguinte forma:

É um docinho, muito bem comportado, um amor, não briga com ninguém, não cria confusão com ninguém, respeita a gente,

\footnotetext{
3 Todos os nomes são fictícios.
} 
respeita os colegas. É uma criança muito tranquila, nota 10 , nota 10 mesmo. E a família, eu não tenho o que reclamar.

A docente comentou que, algumas vezes, ele deixou de levar a atividade de casa respondida, mas, na maioria dos casos, a mãe explicou o que tinha acontecido, deixando até um bilhete na agenda para isso. Daí a satisfação dela ao se remeter a esse educando. Afirmou ter um carinho muito grande por ele. Por isso, mencionou seu nome como um dos dois que poderia ser os ideais na sala de aula.

Falando sobre as expectativas que os docentes têm com relação ao comportamento e desempenho dos seus alunos, a mestra afirmou que algo natural para a maioria dos professores era a curiosidade que eles sentiam com respeito aos seus futuros alunos. Ela mesma afirmou ter grande expectativa pensando no perfil de seus educandos, já que tinha certo contato com eles nas turmas de Jardim I, dentro da escola, cujas salas ficavam de frente para a dela. Sobre esse assunto, realçou, durante a entrevista:

Já fico observando os alunos no Jardim I, porque eu estou ali de frente trabalhando com eles. De certa forma, eu vou até mesmo me aproximando deles para que, no ano que eles forem meus alunos, não ter aquela dificuldade de adaptação em relação ao professor.

Esse contato era importante para ela, porque permitia estar mais familiarizada com os alunos e fazia com que eles se sentissem mais a vontade com ela quando fossem de sua turma. Porém, enfatizou que essa expectativa gerava muitas preocupações. Vejamos o que afirmou a esse respeito:

Quando os vejo lá no Jardim I, que eu vejo que tem aquele que tem muita dificuldade, eu fico pensando: como será que ele vai se desenvolver no Jardim II? Porque a gente está a par da situação deles, das dificuldades, aqueles que têm dificuldade de comportamento, aqueles alunos que têm dificuldade de coordenação motora [...]

De acordo com a professora, as próprias docentes comentavam como era cada aluno dentro da sala, suas dificuldades, seu comportamento. Costumavam comentar: "Olha, ano que vem se prepara, porque fulano é muito difícil, fulana tem muita dificuldade em tal coisa". Mas essa expectativa que ela 
tinha era por causa do seu desejo de que todos os alunos tivessem um bom desenvolvimento, que a turma saísse com um nível bom, que pudessem ir para outra escola bem preparados.

Nesse ponto, em específico, verificamos a pressão que existia, sobretudo por ser uma instituição particular que atendia a educação infantil, bem como os anos iniciais do ensino fundamental quanto à representação que outras instituições teriam quanto ao trabalho desenvolvido. Daí a preocupação da mestra, essencialmente, com o aspecto cognitivo.

Em relação às expectativas e implicações na prática de sala de aula, ela realçou que o correto seria não ter expectativas com relação às crianças, porque isso, na verdade, seria uma forma de (pré)julgá-los, já determinando como seriam. É como se estivéssemos dizendo: "se ele é assim no Jardim I, também será assim no Jardim II". Só que, mais uma vez, ressaltou que isso era quase impossível, porque constantemente estava em contato com eles.

Essa expectativa apresentada pela mestra vinha influenciando sua maneira de ensinar, assim como o tratamento didático com os alunos? Eis o que declarou durante a entrevista:

Essa expectativa pode, sim, influenciar. Pode, de certa forma, causar, não sei, uma frustração, pode causar situações difíceis, porque muitas vezes a gente espera algo de determinado aluno e ele não desenvolve como desenvolvia.

Isso pode trazer grandes efeitos em sala de aula. Um deles, apresentado pela professora, seria o próprio questionamento com respeito a sua metodologia didática adotada em sala de aula. Chegou a comentar que podia acontecer de um aluno se desenvolver muito bem no Jardim I, mas, ao chegar ao Jardim II, não ter o mesmo progresso, frustrando essa expectativa:

Por isso que a gente cria expectativas com relação a um aluno e se decepciona lá na frente, aí tem uma frustração, um problema, porque você cria uma expectativa, mas quando você convive com ele é outra coisa, é outra história. A teoria é uma coisa, a prática é outra, completamente diferente.

Acreditamos ser proveitosa essa reflexão, visto que motiva o professor a mudar e melhorar seu modo de ensinar, adaptando-se a todos os alunos. Por 
outro lado, isso pode gerar um desapontamento quando àquelas crianças em que se têm uma expectativa maior, cujo desenvolvimento é melhor, não alcançam as metas propostas pela professora.

Mas o contrário também pode acontecer. Talvez ela tenha expectativas negativas a respeito de certo aluno que não se desenvolveu tão bem no ano anterior, mas, agora, começa a se desenvolver, melhorar seu comportamento. Isso tudo porque,

de um ano para o outro a criança amadurece muito, ela cresce, desenvolve. Então, às vezes, o comportamento que ele tinha no Jardim I, ele não vai apresentar no Jardim II, por isso, seria melhor que a gente não criasse expectativa em relação aos nossos alunos.

Até mesmo ao longo do ano, a criança pode mudar. Isso pode acontecer com o apoio da professora juntamente com o trabalho da família. A docente assinalou, durante a entrevista, que parte importante do aluno ideal envolve a família. Segundo ela,

a família ideal é aquela que dá esse suporte para o aluno em casa, aquela que acompanha de perto mesmo 0 desenvolvimento dos seus filhos e aquela família que sabe que tem a sua responsabilidade perante aquele aluno e assume essa responsabilidade.

Uma das descrições que fez do aluno José mostrou essa mudança:

[...] no início do ano, a gente conversou com a mãe e com o pai. Eles entenderam que o José precisava de uma mudança [...] Os pais tomaram essa decisão e fizeram em casa algumas coisas que mostraram pra ele que ele precisava mudar, precisava respeitar, mudar o comportamento [...] ele melhorou demais o comportamento, hoje as dificuldades dele estão dentro do padrão, da faixa etária.

A mestra enfatizou, ainda, que ocorreu uma grande variação na atitude dele devido ao trabalho realizado na escola e pela família. Então, a visão que tinha desse aluno mudou ao longo do semestre. Essa atitude de acompanhar e ver o progresso do aluno é extremamente importante, principalmente para o professor de educação infantil, já que essa postura consiste em avaliar o aluno 
e auxiliá-lo no que for necessário ao longo do ano, conforme defende Faria e Besseler (2014).

Esse exemplo mostra a importância de o professor não ter uma atitude fechada com relação aos seus alunos, considerando que seu comportamento e desenvolvimento inicial serão os mesmo até o final do ano. llustra, ainda, a necessidade de não deixar que nossos conceitos prévios sobre as crianças influenciem nossas atitudes em relação a eles e ao ensino, num contexto determinista.

No que diz respeito à relação professor-aluno e aluno-aluno, dentro desse contexto, a professora afirmou acreditar que sua concepção de aluno ideal vinha influenciando sua forma de lidar com os aprendizes. Esse aspecto se evidenciou no momento em que enfatizou que os educadores tinham que tomar cuidado, porque sempre tinha aquele aluno mais carinhoso, que chamava mais a atenção do que outros. De acordo com a mestra, era necessário esse cuidado para que o docente não deixasse que outros educandos percebessem esse sentimento diferenciado. Eis o que declarou durante a entrevista a esse respeito:

Quando eles percebem que o professor, de certa forma, está tratando diferente, seja por causa do aprendizado ou por causa do comportamento, ou por outro motivo qualquer entre eles, acontece desentendimento, que aí eles começam a criar problema com aquele aluno que está sendo mais defendido pela professora.

Um dos relatos trazidos pela professora mostrou as consequências do tratamento diferenciado àquele aluno que tinha características mais esperadas ou desejadas por ela. Relatou que tinha um aluno de tarde que era "muito bonzinho, muito bonzinho mesmo", praticamente não conversava, era muito quietinho, muito na dele, e desde o ano anterior tinha se apaixonado pela criança, "porque ele era muito lindo mesmo". Mencionou, ainda, que já havia tentando se aproximar desse aluno, mas como era muito tímido, não conseguia. Nesse ano que ele passou a ser de sua turma, aos poucos, começou a se aproximar dela. Quando estava entregando as agendas, se 
aproximava dele e permitia que ele as entregasse. No momento em que distribuía as atividades de casa, "ele vinha de mansinho", relatou e, mais uma vez, deixava que entregasse. Porém, com o passar dos dias, a professora começou a notar que ele estava sempre perto dela, desenhando no quadro. Mas como era "muito bonzinho", não tinha coragem de chamar sua atenção.

$\mathrm{Na}$ ocasião em que as demais crianças notaram, fizeram o mesmo, mas a professora sempre dizia: "não, não. Depois a tia deixa todo mundo brincar". Nesse momento, os alunos começaram a perceber que a mestra estava deixando esse aluno fazer as coisas, mas não os outros, e, assim, começaram a reclamar e a dizer: "A tia só gosta dele, a tia só deixa ele desenhar".

Depois disso, começou, aos poucos, a mudar sua postura em relação ao aluno. Conversou com ele, dizendo que depois ia deixar todos juntos irem ao quadro para brincar, mas frisou que ele não poderia ficar lá. Esse exemplo evidenciou que as expectativas podem influenciar diretamente no tratamento didático, na relação professor-aluno em sala de aula. Essa postura se distancia do trabalho didático-pedagógico que visa alcançar todos os aprendizes.

Percebemos, assim, que as expectativas de um educador podem afetar o modo como age e lida com os alunos. Quanto mais idealizarmos um tipo ideal de aluno, maior será nossa frustração, visto que não agiremos de acordo com a singularidade e necessidade de cada educando, e isso pode comprometer o ensino e aprendizagem do mesmo.

A seguir, algumas considerações.

\section{Algumas considerações finais}

Diante do que foi tecido nesse estudo, foi possível problematizar as relações de sala de aula, com foco específico ao aluno considerado ideal pelo professor. Consequentemente, a verificar o quanto o tratamento didático adotado pelo professor tem estreita relação com suas concepções de infância, bem como com suas expectativas de aprendizagem.

Essa pesquisa objetivou analisar o olhar do educador sobre o aluno ideal, buscando trazer maiores contribuições para as questões: A infância é 
valorizada em sala de aula? A expectativa do professor sobre seus alunos influencia em sua maneira de ensinar e tratar os alunos reais que estão nas salas de aula? Qual o conceito de aluno ideal do ponto de vista do professor? Tais indagações nos impulsionaram a acompanhar a prática da professora contribuinte com a pesquisa, bem como entrevistá-la.

A partir das análises, conseguimos verificar que houve mudança acerca do conceito de infância e como a criança vem sendo tratada na contemporaneidade. Os professores parecem estar preocupados com o que acontece com elas em sala, ansiosos em ver seu aprendizado e desenvolvimento. Diante de um campo multifacetado, é possível apreender avanços nesse sentido.

Observando as concepções da professora que participou da pesquisa, ficou evidente que, para ela, o aluno ideal realmente atendia às dimensões: cognitiva e comportamental. Porém, aquele que não apresentava essas características, se distanciava desse conceito defendido pela mestra.

Compreendemos, por meio da realização desse estudo, que essas expectativas influenciam, sim, no modo de tratar os alunos e, até mesmo, a forma como se relacionam entre si. Nos relatos, verificamos que os aprendizes que eram mais parecidos com o modelo de ideal, eram tratados de forma diferente, sendo privilegiados pela professora. Com isso, os outros aprendizes denunciavam tal postura por parte da docente. Acreditamos que esse cenário precisa ser refletido pelo professor, na tentativa de criar um clima de interação em sala de aula, não de competitividade.

Para a mestra, a infância está diretamente relacionada com a criança. Dentro da sala, explicou que tais comportamentos eram comuns, mas que ela precisava saber controlar para que, na hora de estudar, eles ficassem sentados e prestassem atenção. Desse ponto de vista, notamos que o brincar não fazia parte das estratégias pedagógicas, até porque não havia, conforme relatos da professora, articulação entre as dimensões: educar, cuidar e brincar. Isso diverge do que trouxemos no aporte teórico, visto que os autores defendem a importância da brincadeira para o desenvolvimento e aprendizado do aluno. 
Sabemos que não é fácil o professor estar em sala e aqui não queremos criticar seu trabalho, mas é preciso enfatizar que os modos diferenciados de fazer, de praticar, priorizando o prazer em aprender, são cruciais no processo de ensino-aprendizagem. O professor pode refletir acerca da heterogeneidade de sua turma e, com base nessa prerrogativa, criar estratégias didáticas e pedagógicas que contemplem esse universo.

\section{Referências}

ARIÈS, P. História Social da Criança e da Família. Tradução por: Dora Flasksman. $2^{a}$ ed. Rio de Janeiro: LTC- Livros Técnicos e Científicos Editora S.A. 1981.

BRASIL. Constituição da República Federativa do Brasil. Brasília, DF: Senado Federal, 1988.

BRASIL. Ministério de Educação e Cultura. Lei de Diretrizes e Bases da Educação Nacional - Lei no 9.394/96 de 20 de dezembro de 1996. Brasília: MEC, 1996.

BZUNECK, J. A. As Crenças de auto eficácia dos professores. In: F.F. Sis-to; G. C. Oliveira. (Orgs.). Leituras de Psicologia para Professores. Petrópolis: Vozes, 2001.

CARVALHO, J. N. M. Concepções de infância e educação infantil: reflexões iniciais. IV Seminário Povos Indígenas e Sustentabilidade: Saberes tradicionais e formação acadêmica, Campo Grande/MS, 2011.

DEL PRIORE, M. História da criança no Brasil. São Paulo: Contexto, 1991.

FARIA, A. L. G. O espaço físico como um dos elementos fundamentais para uma pedagogia da educação infantil. In: FARIA, A. L. G., PALHARES, M. S. (orgs.). Educação infantil pós-LDB: rumos e desafios. Campinas, São Paulo: Autores Associados, 2005.

FARIA, A. P; BESSELER, L. H. A avaliação na educação infantil: fundamentos, instrumentos e práticas pedagógicas. Nuances: estudos sobre Educação. Presidente Prudente: v. 25, n. 3, set./dez. 2014., p. 155- 169.

GERHARDT, T. E.; SILVEIRA, D. T. Métodos de Pesquisa. Porto Alegre: Editora da UFRGS, 2009.

HEYWOOD, C. A History of childhood: children and childhood in the west from medieval to modern times. Cambridge e Malden: Polity, 2001.

NASCIMENTO, C. T.; BRANCHER, V. R.; OLIVEIRA, V. F. A construção social do conceito de infância: uma tentativa de reconstrução historiográfica. Linhas,

Florianópolis, v.9, n.1, jan./jun. 2008., p.04-18,

NEVES, J. G. O erro construtivo e o castigo na escola. Revista Iberoamericana de Educación, 2005.

PASCHOAL, J.; MACHADO, M. A História da Educação Infantil no Brasil: avanços, retrocessos e desafios dessa modalidade educacional. Revista HISTEDBR On-line, Campinas, n.33, mar. 2009., p.78-95, 
STRAZZACAPPA, M. A educação e a fábrica de corpos: a dança na escola. Caderno CEDES, 2001, vol.21, n.53, p.69-83.

UNIVALI, M. H. C.; DONADUZZI, A. Em Busca do aluno ideal: expectativas de professoras de pré-escolar sobre seus alunos. Anais da 5ª Reunião Anped Sul, 2009. 